\title{
Behavior of Platinum Group Metals during Their Pyrometallurgical Recovery from Spent Automotive Catalysts
}

\author{
Georgios Kolliopoulos', Efthymios Balomenos', Ioanna Giannopoulou1, \\ Iakovos Yakoumis ${ }^{2}$, Dimitrios Panias ${ }^{1}$ \\ ${ }^{1}$ School of Mining and Metallurgical Engineering, National Technical University of Athens, Zografou Campus, \\ Athens, Greece \\ ${ }^{2}$ MONOLITHOS Catalysts and Recycling Ltd, Athens, Greece \\ Email: panias@metal.ntua.gr
}

Received 10 May 2014; revised 20 June 2014; accepted 1 August 2014

Copyright (C) 2014 by authors and OALib.

This work is licensed under the Creative Commons Attribution International License (CC BY). http://creativecommons.org/licenses/by/4.0/

(c) (i) Open Access

\section{Abstract}

The behavior of platinum group metals (PGMs) during their recovery with smelting of spent automotive ceramic catalysts powder in the presence of metallic copper at elevated temperatures is studied in this paper. Two different metal recovery mechanisms proved to be active in this process: 1) Wetting of micro-dispersed particulates of PGMs in the slag by molten copper, formation of copper droplets with attracted microparticles of PGMs and settling of the molten droplets of CuPGMs alloy through the slag at the bottom of the crucible ("wetting"); 2) Settling of solid PGMs microparticles through the molten slag and formation of a solid solution with the molten copper at the bottom of the crucible ("settling"). The PGMs are divided in two separate groups. Platinum has under the same experimental conditions substantially higher recovery in comparison with the palladium and rhodium that behave as a group having almost identical recoveries. The heavier Pt is recovered primarily in big extent (almost 88\%) through the "settling" mechanism while Pd and $\mathrm{Rh}$ are recovered following a more balanced mixture of both mechanisms with the "settling" one to be again more important (66\% for Pd and $57 \%$ for $\mathrm{Rh}$ ). Slag viscosity is the most important physical property and the design of an appropriate slag system is the most important issue in developing an efficient process for the recovery of PGMs.

\section{Keywords}

Platinum Group Metals, Palladium, Rhodium, Spent Automotive Catalysts

Subject Areas: Chemical Engineering \& Technology, Mineral Engineering

How to cite this paper: Kolliopoulos, G., Balomenos, E., Giannopoulou, I., Yakoumis, I. and Panias, D. (2014) Behavior of Platinum Group Metals during Their Pyrometallurgical Recovery from Spent Automotive Catalysts. Open Access Library Journal, 1: e736. http://dx.doi.org/10.4236/oalib.1100736 


\section{Introduction}

Catalytic converters are devices that control the exhaust emissions of an internal combustion engine by converting the exhaust toxic gasses into less toxic substances. Since 1994, when the European Directive 94/12/EEC (on ambient air quality) was laid down, all the motors produced or imported in EU have been obliged to be fitted with catalytic converters that reduce emissions of carbon monoxide, hydrocarbons and nitrogen oxides below the legislative levels. Today, the mostly used automotive catalytic converters are the "three-way converters" (TWC), which are comprised of platinum group metals (PGMs) namely, Platinum (Pt), Palladium (Pd) and Rhodium (Rh). Among these metals, Pt is the most active catalyst and is used both as an oxidation and as a reduction catalyst; Pd is used as an oxidation catalyst and Rh, as a reduction one.

Commercial automotive catalysts are separated in two different categories, depending on the substrate which is implemented. The most common catalytic converters (i.e. 90\% of the cases) are the ones using ceramic substrate, while a minority of the used converters has metallic substrate. Metallic substrate converters have a substantially smaller part of the market due to the fact that they implement more expensive raw materials, the impregnation of the PGMs is more difficult and the recycling of PGMs is not such effective as in ceramic substrate case. However, they have significant advantages in terms of temperature tolerances which are crucial for closecoupled (near the engine) applications. Although there is a wide variety of possible combinations of PGMs in the catalytic converters, bibliographic data suggest that the total content of these metals is up to $2000 \mathrm{ppm}$ in the ceramic substrate [1]. This figure is close to the reality as is shown in Table 1, where the PGMs concentrations (assaying in certified laboratories) of 10 typical consignments of spent ceramic catalytic converters, recycled from the Greek Market by Monolithos Ltd., are presented.

Based on the above data, the mean mass ratio of the three metals $\mathrm{Pt} / \mathrm{Pd} / \mathrm{Rh}$ is $2.4 / 5.4 / 1$. This analogy is highly dependent on the commercial price of each metal. In the beginning of the decade of 2000, when Palladium was more expensive than Platinum, the analogy of $\mathrm{Pt} / \mathrm{Pd} / \mathrm{Rh}$ was $4 / 2.9 / 1$, as is shown in Table 2. This fact proves that the catalytic converter manufacturing industry possesses the required knowledge of switching between Palladium and Platinum depending on the market prices of the metals. Finally, the Rhodium content in spent ceramic catalytic converters seems to be almost constant at around $296 \mathrm{ppm}$.

On the contrary, in the case of metallic catalysts the actual concentration of PGMs in the metallic substrate cannot be easily calculated because the metallic canister of the converter cannot be separated from the foil (substrate) and thus, the metallic converters are driven to recycling process containing their canister. The amount of PGMs in four typical metallic converter consignments, recycled for the Greek Market by Monolithos Ltd is shown in Table 3. The mean mass ratio of $\mathrm{Pt} / \mathrm{Pd} / \mathrm{Rh}$ contained in metallic converters is $2.2 / 8.5 / 1$. Based on the data presented in Table 3, the commercial metallic automotive catalysts contain $1657 \mathrm{~g}$ of PGMs per catalytic converter in comparison to $1.885 \mathrm{~g}$ of PGMs per ceramic catalytic converter.

In both cases, the PGMs concentration is significantly higher than the one of the primary ores that is on average 5 - 20 ppm [2] [3]. The high intrinsic metal values make recycling attractive from an economic point of view [4]. In addition, due to the much higher concentration compared to the mined ores, recycling also helps to reduce the environmental burden of metal supply significantly, especially with the respect to the impact on climate [1] [3] [5] [6].

Effective PGMs recycling from spent automotive catalysts requires a well-tuned recycling chain, consisting of the following specialized stages: 1) Collection of the converters from the scrap yards of the car workshops as well as the ELV authorized treatment facilities, 2) Sorting and dismantling of the converters, 3) Crushing, milling, homogenization, sampling and assaying, 4) PGMs Recovery and refining. PGMs recovery from spent automotive catalysts is dominated by big integrated smelters-refineries such as Umicore and Johnson Matthey in Europe, MultimetcoInc and Techemet in USA and Nippon PGM Co in Japan. Hydro- and Pyrometallurgical processes are applied for recovery of PGMs from spent automotive catalysts. Hydrometallurgical methods are rarely applied to recycle PGMs [4]. They are based on leaching spent automotive catalysts powder with several leaching agents in combination with oxidants. Hydrochloric acid is the most used leaching agent while nitric acid, chlorine and hydrogen peroxide are the most common oxidants [4] [7] [8]. Spent automotive catalysts pretreatments for enhancing the leaching efficiency of PGMs have been studied. Among them, the metal vapour treatment [9] and the carbochlorination [10] one are the most interesting. Pyrometallurgical methods are normally used for the PGMs recovery [4] [5] [8] [11] [12]. The milled monoliths are melted in the presence of a metal collector (such as $\mathrm{Cu}$, Fe, used printed circuitsetc) or a metal oxide ( $\mathrm{CuO}$ or $\mathrm{Fe}_{2} \mathrm{O}_{3}$ )/coke mixture (Rose 
Table 1. PGMs concentrations in spent ceramic catalytic converters recycled from the Greek market (Data from Monolithos Ltd).

\begin{tabular}{ccccccc}
\hline A/A & Number of Ceramic Converters & Weight of Ceramic Monolith (kg) & Pt (ppm) & Pd (ppm) & Rh (ppm) & Total PGMs (ppm) \\
\hline 1 & 1600 & 1212.27 & 724 & 1633 & 302 & 2659 \\
2 & 1597 & 1181.75 & 731 & 1521 & 255 & 2507 \\
3 & 1526 & 1127.28 & 760 & 1620 & 305 & 2685 \\
4 & 1374 & 1012.12 & 673 & 1734 & 315 & 2722 \\
5 & 1377 & 1010.76 & 710 & 1471 & 295 & 2476 \\
6 & 1516 & 1120.41 & 734 & 1522 & 285 & 2541 \\
7 & 1383 & 1008.89 & 705 & 1606 & 283 & 2594 \\
9 & 1369 & 985.09 & 749 & 1573 & 308 & 2630 \\
10 & 1476 & 1032.44 & 630 & 1760 & 299 & 2689 \\
\hline
\end{tabular}

Table 2. PGMs concentrations of 6 typical consignments of spent ceramic catalytic converters recycled from the Greek market by Monolithos Ltd., in the beginning of the decade of 2000.

\begin{tabular}{ccccccc}
\hline A/A & Number of Ceramic Converters & Weight of Ceramic Monolith (kg) & Pt (ppm) & Pd (ppm) & Rh (ppm) & Total PGMs (ppm) \\
\hline 1 & 1536 & 1222.65 & 1239 & 855 & 297 & 2391 \\
2 & 1468 & 1170.35 & 1158 & 817 & 291 & 2266 \\
3 & 1367 & 1090.10 & 1198 & 859 & 302 & 2359 \\
4 & 1347 & 1104.00 & 1257 & 885 & 316 & 2458 \\
5 & 1474 & 1156.90 & 1113 & 813 & 280 & 2206 \\
6 & 1462 & 1153.95 & 1071 & 799 & 271 & 2141 \\
\hline
\end{tabular}

Table 3. PGMs content in four different typical metallic converter consignments, recycled for the Greek Market by Monolithos Ltd.

\begin{tabular}{cccc}
\hline Number of Metallic Catalysts & Pt (g) & Pd (g) & Rh (g) \\
\hline 618 & 179.69 & 615.61 & 73.71 \\
484 & 161.33 & 585.41 & 75.43 \\
482 & 126.94 & 722.96 & 77.71 \\
445 & 168.37 & 515.92 & 58.97 \\
\hline
\end{tabular}

method) and appropriate fluxes in order for the PGMs to be collected by the carrier metal forming an alloy phase which is separated from the slag that contains the fluxes and the ceramic components of the monoliths. The alloy is further refined in order pure PGMs to be produced.

This work deals with the study of the PGMs behavior during their pyrometallurgical recovery from spent ceramic catalytic converters utilizing copper as a metallic collecting phase.

\section{Experimental}

\subsection{Materials}

The sample of the spent automotive catalysts used in this work was supplied by the Greek company Monolithos Ltd and was originated from a consignment of spent ceramic catalytic converters recycled from the Greek mar- 
ket. The as received material was crushed by Monolithos Ltd and then milled to $-250 \mu \mathrm{m}$. The mean particle size, d50, of powder material measured by the Malvern Mastersizer Laser particle size analyzer was $42.75 \mu \mathrm{m}$. The chemical analysis of powder material performed by Spectro Xepos XRF spectrometer is shown in Table 4. Standard automotive catalyst powders supplied by NIST were used for the calibration of XRF spectrometer. The analytical error was $\pm 2.5 \%$ on the measured value at $95 \%$ confidence level. The carbon and sulfur content were measured in Leco CS-200 analyzer.

The spent automotive catalyst powder is primarily composed from $\mathrm{SiO}_{2}, \mathrm{Al}_{2} \mathrm{O}_{3}$ and $\mathrm{MgO}$. Those three components are the main components of the cordieritic monoliths that are used for the manufacturing of ceramic catalytic converters. In addition, the powder contains $\mathrm{ZrO}_{2}, \mathrm{CeO}_{2}, \mathrm{BaO}$ and $\mathrm{La}_{2} \mathrm{O}_{3}$ which are components normally used together with $\gamma$-alumina for the preparation of washcoat. Phosphorous and zinc are two components which are attributed to the compound zinc dialkyl dithio phosphate (ZDDP) that is used as a lubricant in automobile motors. Sulfur and carbon are directly attributed to the burnt fuel. Finally, the spent automotive catalyst powder contains 1364 ppm Pt, 754 ppm Pd and 275 ppm Rh.

Chemically pure sodium hydroxide and silica were used as fluxes for the control of the rheological properties of slag that was produced during the pyrometallurgical treatment of spent automotive catalyst powder. Pure copper powder (-32 mesh and 99.5\% purity) were used as a PGMs collecting phase during the smelting experiments.

\subsection{Experimental Procedure}

The smelting experiments were performed in a muffle furnace reaching a temperature of $1700^{\circ} \mathrm{C}$. A simplified flowsheet is shown in Figure 1. The furnace was purged continuously with nitrogen, in order to establish an inert atmosphere in the reactor. The feeding material was prepared by mixing $50 \mathrm{~g}$ of spent automotive catalyst powder with the fluxes, namely $15 \mathrm{~g} \mathrm{SiO}_{2}$ and $10 \mathrm{~g} \mathrm{NaOH}$. After homogenization and in the standard experimental protocol, the mixture was placed inside a graphite cylindrical crucible with an internal diameter of $10 \mathrm{~cm}$ and a height of $50 \mathrm{~cm}$ and then, $10-20 \mathrm{~g}$ of copper powder were placed on top of it. In some different experimental set-ups the copper powder were mixed together with the spent automotive catalyst powder and the fluxes or placed at the bottom of the crucible below the feeding mixture. The process temperature was varied from $1450^{\circ} \mathrm{C}$ to $1600^{\circ} \mathrm{C}$ while the retention time at process temperature varied in-between 30 and $120 \mathrm{~min}$. At the end of each experiment, the crucible was cooled down slowly to ambient temperature. Then, the crucible was broken down and the slag was carefully separated from the metallic copper phase. The slag was crushed and powdered and the PGMs content in it was determined by XRF spectrometry.

\section{Results and Discussion}

Four different experimental series were performed in order to elucidate the mechanisms of PGMs recovery from spent ceramic automotive catalysts. The three first experimental series studied the effect of process parameters, such as smelting temperature and duration as well as the amount of added carrier metal, on the efficiency of PGMs recovery. The last one studied the effect of different experimental set-ups on the PGMs recovery.

\subsection{Effect of Smelting Temperature on PGMs Recovery}

The effect of smelting temperature on PGMs recovery is shown in Figure 2. Smelting temperature affects dras-

Table 4. Chemical analysis of spent automotive catalysts powder.

\begin{tabular}{cccccccc}
\hline Chemical Species & $\% \mathrm{w} / \mathrm{w}$ & Chemical Species & $\% \mathrm{w} / \mathrm{w}$ & Chemical Species & $\% \mathrm{w} / \mathrm{w}$ & Chemical Species & $\% \mathrm{w} / \mathrm{w}$ \\
\hline $\mathrm{SiO}_{2}$ & 35.33 & $\mathrm{Na}_{2} \mathrm{O}$ & 2.38 & $\mathrm{ZnO}$ & 0.33 & $\mathrm{C}$ & 0.43 \\
$\mathrm{Al}_{2} \mathrm{O}_{3}$ & 37.15 & $\mathrm{CaO}$ & 1.16 & $\mathrm{BaO}$ & 0.77 & $\mathrm{Pt}$ & 0.1364 \\
$\mathrm{MgO}$ & 8.51 & $\mathrm{Fe}_{2} \mathrm{O}_{3}$ & 2.44 & $\mathrm{La}_{2} \mathrm{O}_{3}$ & 0.29 & $\mathrm{Pd}$ & 0.0754 \\
$\mathrm{ZrO}_{2}$ & 4.55 & $\mathrm{TiO}_{2}$ & 0.29 & $\mathrm{P}$ & 0.79 & $\mathrm{Rh}$ & 0.0275 \\
$\mathrm{CeO}_{2}$ & 3.51 & $\mathrm{Cr}_{2} \mathrm{O}_{3}$ & 0.8 & $\mathrm{~S}$ & 0.44 & Total & $\mathbf{9 9 . 4 1}$ \\
\hline
\end{tabular}




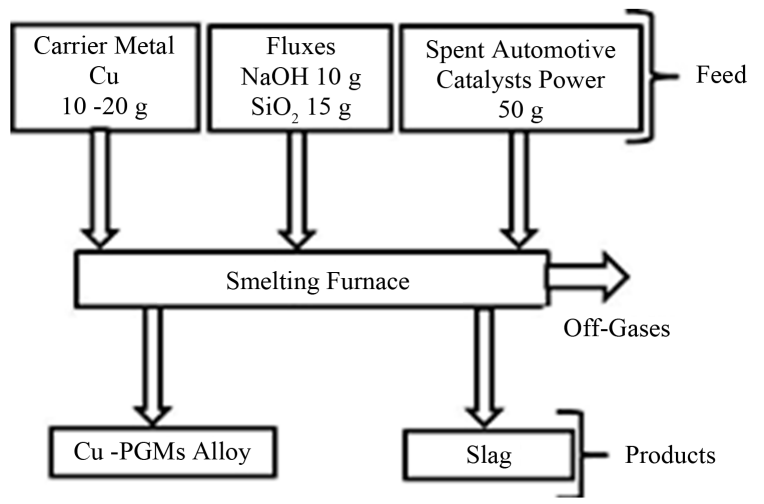

Figure 1. Simplified flowsheet of the pyrometallurgical process.

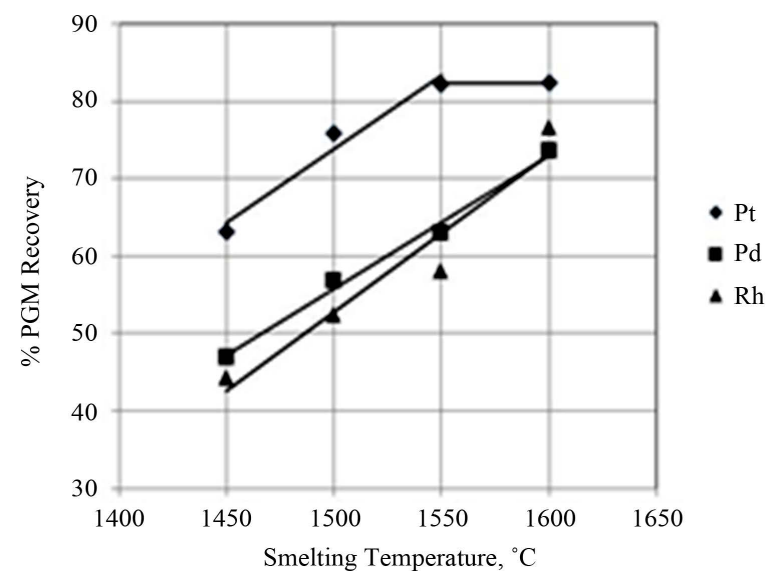

Figure 2. Effect of smelting temperature on PGMs recovery (Standard Experimental set-up, $10 \mathrm{~g}$ of copper, $30 \mathrm{~min}$ ).

tically the recovery of Pt, Pd and Rh. In general, the temperature increase causes an increase to the PGMs recoveries. The PGMs are divided in two separate groups. Platinum has always substantially higher recovery in comparison with the other metals. In case of Pt, temperature seems to affect the metal recovery in the range $1450^{\circ} \mathrm{C}-1550^{\circ} \mathrm{C}$ while at higher temperatures there is not any improvement in metal recovery. Palladium and rhodium seem to follow identical behavior during smelting. Their recoveries are linearly increased as a function of smelting temperature within the whole range of the temperature studied following identical slopes. In addition, this slope seems to fit well with the one observed in the case of the Pt. In order to comprehend the beneficial effect of temperature on the PGMs recovery, it is necessary to take into account the two different prevailing mechanisms during the recovery of metals:

1) Wetting of micro-dispersed particulates of PGMs in the slag by molten copper, formation of copper droplets with attracted microparticles of PGMs and settling of the molten droplets of Cu-PGMs alloy through the slag at the bottom of the crucible ("wetting”).

2) Settling of solid PGMs microparticles through the molten slag and formation of a solid solution with the molten copper at the bottom of the crucible ("settling").

Both mechanisms are based on settling of a heavier metallic phase (molten droplets of Cu-PGMs alloy or solid PGMs microparticles) through a liquid slag phase due to their gravity difference as is seen in Table 5. Assuming spherical particles and low Reynolds number $(\operatorname{Re}<1)$, the approximation of Stokes Law can be used for the estimation of the terminal velocity of metallic phases during their settling through molten slag from the followingequation [13] [14]:

$$
u_{t}=\frac{\left(\rho_{\text {metallic phase }}-\rho_{\text {slag }}\right) D^{2} g}{18 \mu}
$$


Table 5. Physical properties of several phases during smelting of spent automotive catalysts.

\begin{tabular}{cccc}
\hline Phase & Melting Point $\left({ }^{\circ} \mathrm{C}\right)$ & Density as solid $\left(\mathrm{kg} / \mathrm{m}^{3}\right)$ & Density as liquid $\left(\mathrm{kg} / \mathrm{m}^{3}\right)$ \\
\hline $\mathrm{Cu}$ & 1084.82 & 8920 & 8020 \\
$\mathrm{Pt}$ & 1768.3 & 21,090 & 19,770 \\
$\mathrm{Pd}$ & 1554.9 & 12,023 & 10,380 \\
$\mathrm{Rh}$ & 1964 & 12,450 & 10,700 \\
& Solidus: 1040 & & \\
\hline
\end{tabular}

where, $u_{t}$ denotes the terminal velocity; $\rho$ the density; $D$ the droplet or particle diameter; $g$ the gravitational constant and $\mu$ the slag absolute viscosity.

The two most important physical properties in the settling process are the density difference between the phases and the slag absolute viscosity. In general, the separation of phases become easier (high terminal velocity values) as the density difference increases and the slag viscosity decreases. At a given smelting temperature the slag viscosity is constant and then the key parameter for the settling process is the density difference between the phases. If the only participating mechanism for PGMs recovery was the "wetting" one, then the molten droplets of Cu-PGMs alloy would have almost constant density around the one of the molten copper (because the mass ratio of PGMs/Cu is always less than 0.01) and thus all the PGMs would settling with almost the same terminal velocity and therefore they would have approximately the same recovery values. This is no true as is seen in Figure 2 where platinum demonstrates substantially higher recoveries under the same experimental conditions. This observation comprises an indirect proof of the existence of both PGMs recovery mechanisms; the "wetting" and "settling" ones. In "settling" mechanism the density of specific PGMs particles have to be taken into consideration. As Pt has significantly higher density in relation to the other two metals (Pd and $\mathrm{Rh}$ ) as is seen in Table 5, its settling velocity and recovery will be substantially higher to the ones of the other PGMs under the same experimental conditions. On the contrary, Pd and Rh have identical densities and therefore under the same experimental conditions will behave as a group with significantly lower gravitational settling driving force and recoveries as is shown in Figure 2. The temperature increase improves substantially the PGMs recoveries. This is attributed to the beneficial effect of temperature on the slag viscosity as it was calculated through the Fact Sage TM 6.4 thermochemical software and database package (www.factsage.com) and is shown in Figure 3. It is observed that the temperature increase in the range $1450^{\circ} \mathrm{C}-1600^{\circ} \mathrm{C}$ causes a significant decrease (at least four times) to the slag viscosity and thus according to the Equation (1) the settling terminal velocity increases substantially amplifying the recovery values of all PGMs with almost a similar way (identical slopes in Figure 2). Moreover, in the temperature range $1550^{\circ} \mathrm{C}-1600^{\circ} \mathrm{C}$ the slag viscosity effect is marginal (Figure 3) and due to the existing very high gravitational settling driving force for Pt it becomes negligible (from experimental point of view) on the Pt recovery value. This is not the case for the other two PGMs due to their significantly lower gravitational settling driving force which renders visible the slag viscosity effect.

\subsection{Effect of Smelting Duration on PGMs Recovery}

The effect of smelting duration on PGMs recovery at $1550^{\circ} \mathrm{C}$ is shown in Figure 4. Smelting duration affects significantly the recoveries of all PGMs. A linear dependence between the recoveries and the retention time on smelting temperature is observed for all metals. Once more, platinum has substantially higher recoveries in comparison with the other metals which behave as a group, indicating again the presence of the existence of both PGMs recovery mechanisms. The terminal settling velocity under constant temperature (and thus constant viscosity) is constant for each specific metal and depends on the density difference between the phases. The PGMs mass flow rate is proportional to the terminal settling velocity which means that the mass transferred is proportional to the terminal settling velocity as well as the retention time. This explains the observedlinearity in Figure 4 as well as the higher recoveries of Pt in relation to Pd and Rh. The line slope in case of Pt is 2.6 - 3 timeslowerthan the ones of $\mathrm{Pd}$ and $\mathrm{Rh}$ which is attributed to the very fast platinum settling in relation to the other metals, which does not permit significant recovery increase as a function of smelting time. 


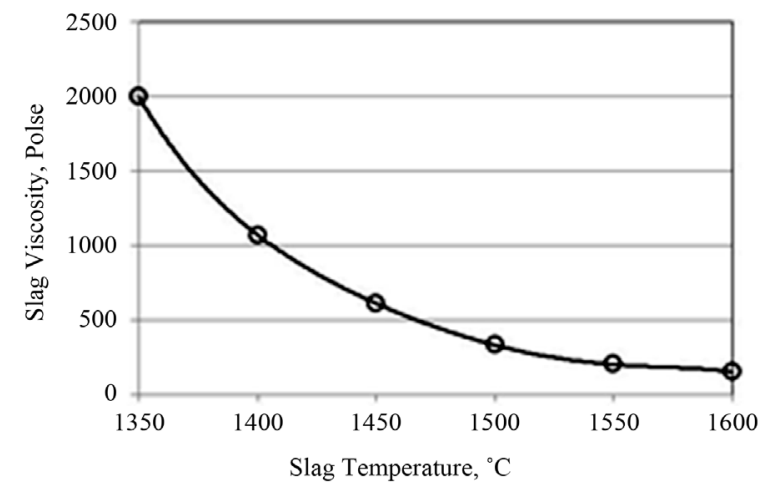

Figure 3. Slag viscosity as a function of process temperature.

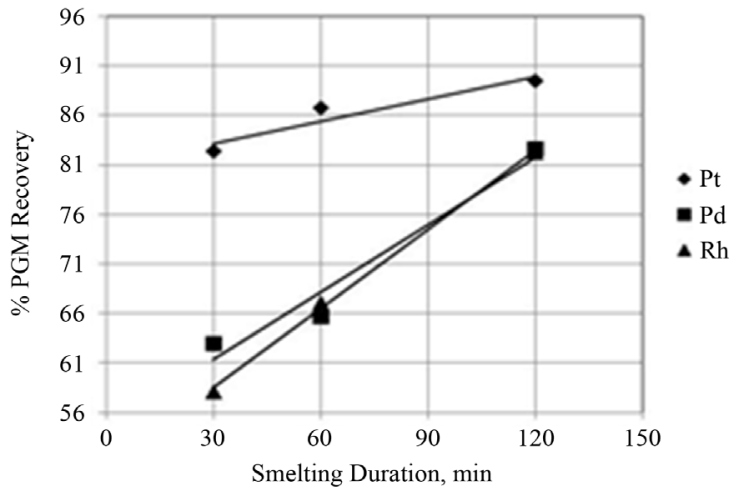

Figure 4. Effect of smelting duration on PGMs recovery (Standard Experimental set-up, $10 \mathrm{~g}$ of copper, $1550^{\circ} \mathrm{C}$ ).

\subsection{Effect of Carrier Metal Amount on PGMs Recovery}

The effect of carrier metal amount on PGMs recovery at $1550^{\circ} \mathrm{C}$ and 30 min retention time at smelting temperature is shown in Figure 5. The effect is not monotonous and seems to be beneficial for all PGMs till the addition of $30 \%$ in relation to the amount of the spent automotive catalysts powder (15 g of copper). Higher amount of carrier metal let unaffected the recoveries of PGMs. PGMs are divided again into the same two groups. Pt has significantly higher recoveries in comparison with the other metals that behave as a group. The amount of carrier metal affects only the mechanism of "wetting" and seems to be more beneficial for the group of Pd and Rh rather than the Pt. This observation indicates that the relevant importance of "wetting" and "settling" mechanisms is not the same for all the PGMs. The lighter PGMs (Pd and Rh) that are settled with substantially lower velocities are potentially more affected by the "wetting" mechanism rather than the heavier Pt that has the ability to settle faster and therefore to avoid in a bigger extent the "wetting" mechanism.

\subsection{Effect of Different Experimental Set-Ups on PGMs Recovery}

In order to elucidate the relevant importance of "wetting" and "settling" mechanisms for each specific PGM three different experimental set-ups were studied. In the standard experimental set-up ( $\mathrm{Cu}$ on top of feeding material) both "wetting" and "settling" mechanisms are present as it was proved in the previous sections. In the second experimental set-up copper was mixed with the feeding material while in the third one copper was put at the bottom of the crucible below the feeding mixture in order to deactivate the "wetting" mechanism. The results are presented in Figure 6.

The first two set-ups gave identical results without noteworthy differences in PGMs recoveries. The deactivation of the "wetting" mechanism (third set-up) affected drastically the recoveries of Pd and Rh which were decreased $30 \%-40 \%$ in relation to the standard experimental set-up. The Pt recovery was reduced only to an amount of $12 \%$ in relation to the standard experimental set-up. As it was observed also in Section 3.3, the heavier 


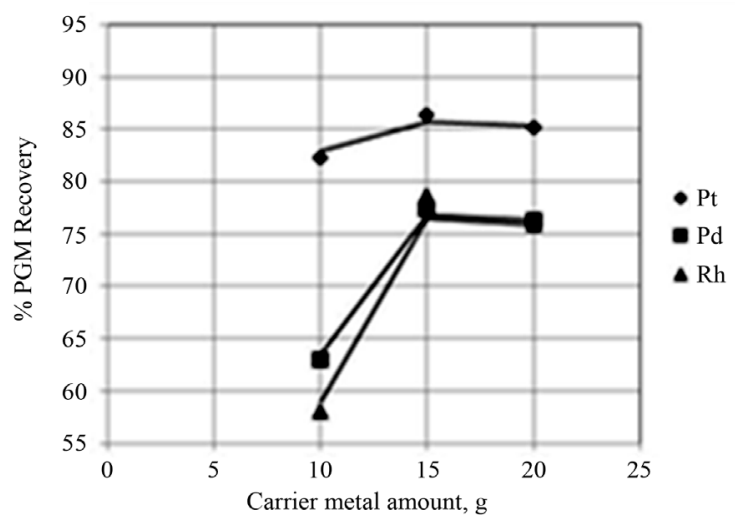

Figure 5. Effect of carrier metal amount on PGMs recovery (Standard Experimental set-up, $30 \mathrm{~min}, 1550^{\circ} \mathrm{C}$ ).
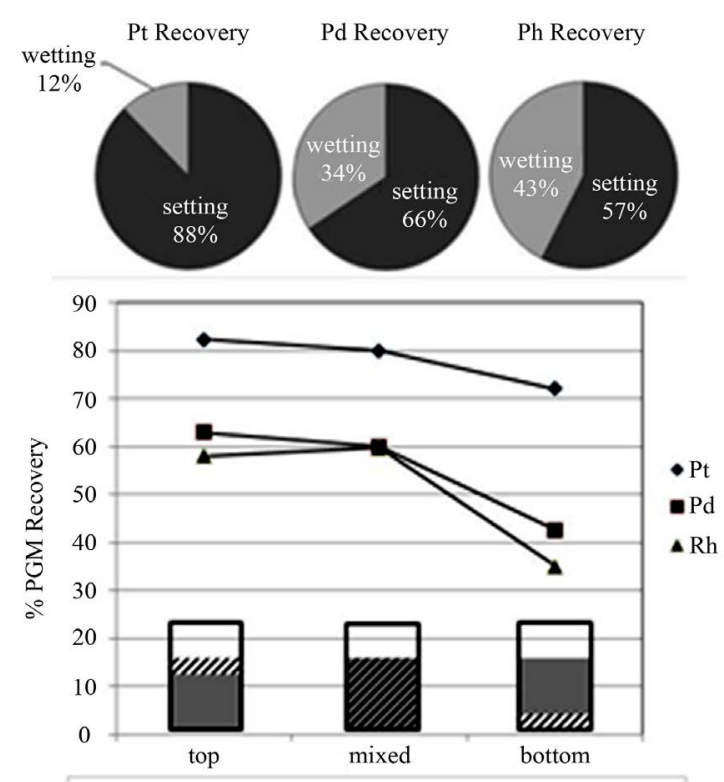

Set up of Carrier Metal ( $/ / A$ and Feeding Material $\square$

Figure 6. Effect of experimental set-ups on PGMs recovery (30 $\min , 1550^{\circ} \mathrm{C}, 10 \mathrm{~g}$ of copper).

Pt is recovered primarily in big extent (almost 88\%) through the "settling" mechanism as is seen in Figure 6. This is exclusively attributed to the very big density difference between solid Pt $\left(21,090 \mathrm{~kg} / \mathrm{m}^{3}\right)$ and liquid $\mathrm{Cu}$ $\left(8020 \mathrm{~kg} / \mathrm{m}^{3}\right)$ that renders solid Pt particles to settle down significantly faster than the copper droplets. The small effect of the "wetting" mechanism is attributed to the fact that copper melts before slag at lower temperatures (Table 5) and therefore start settling before the solid Pt particles. Due to substantially less density difference in-between solid Pd, Rh and liquid Cu (Table 5), Pd and Rh are recovered following a more balanced mixture of both mechanisms with the "settling" one to be again more important (66\% for Pd and 57\% for Rh).

\section{Conclusions}

Two different mechanisms proved to be active during the recovery of PGMs with smelting of spent automotive ceramic catalysts powder in the presence of metallic copper at elevated temperatures:

1) Wetting of micro-dispersed particulates of PGMs in the slag by molten copper, formation of copper droplets with attracted microparticles of PGMs and settling of the molten droplets of Cu-PGMs alloy through the slag at the bottom of the crucible ("wetting"). 
2) Settling of solid PGMs microparticles through the molten slag and formation of a solid solution with the molten copper at the bottom of the crucible ("settling”).

PGMs are divided in two groups. The heaviest platinum can achieve high terminal settling velocities and therefore substantially higher recoveries under the same experimental conditions in relation to the lighter PGMs such as palladium and rhodium which behave as a group exhibiting identical recoveries.

The most important parameters affecting the PGMs pyrometallurgical recovery are the temperature and the retention time on process temperature. The process temperature affects the slag viscosity which is the most important physical property in the studied system. High slag viscosity renders the PGMs recovery process ineffective due to insufficient metallic phase/slag separation, prolong significantly the retention time on process temperature and necessitates excessively high process temperatures. Therefore, the design of the slag system through the use of appropriate fluxes is the most important issue in designing a process for the recovery of PGMs with smelting of spent automotive ceramic catalysts powder in the presence of metallic copper.

\section{Acknowledgements}

The research leading to these results has received funding from the European Union Seventh Framework Programme ([FP7/2007-2013]) under grant agreement no NMP3-SL-2011-280890.

\section{References}

[1] Hagelueken, C. (2012) Recycling the Platinum Group Metals: A European Perspective. Platinum Metals Review, 56, 29-35. http://dx.doi.org/10.1595/147106712X611733

[2] Seymour, R.J. and O’Farrelly, J. (2012) Platinum-Group Metals. In: Kirk-Othmer Encyclopedia of Chemical Technology, John Wiley and Sons, Inc., Hoboken, 1-37.

[3] Kuhn, M. (2013) Recovery of Scarce Metals from ELVs: A Bumpy Road Ahead. Recycling International, 3, 22-23.

[4] Rumpold, R. and Antrekowitsch, J. (2012) Recycling of Platinum Group Metals from Automotive Catalysts by an Acidic Leaching Process. Proceedings of the 5th International Platinum Conference "A Catalyst for Change", Sun City, September 2012, 695-714.

[5] Fornalczyk, A. and Saternus, M. (2013) The Possibilities of Reusing the Ceramic Carriers Coming from Used Auto Catalytic Converters. Advances in Ceramic Science and Engineering, 2, 56-63.

[6] Mouza, A.A., Peolides, C.A. and Paras, S.V. (1995) Utilization of Used Auto-Catalytic Converters in Small Countries: The Greek Paradigm. Resources, Conservation and Recycling, 15, 95-110. http://dx.doi.org/10.1016/0921-3449(95)00023-C

[7] De Aberasturi, D.J., Pinedo, R., De Larramendi, I.R., De Larramendi, J.I.R. and Rojo, T. (2011) Recovery by Hydrometallurgical Extraction of the Platinum-Group Metals from Car Catalytic Converters. Minerals Engineering, 24, 505513. http://dx.doi.org/10.1016/j.mineng.2010.12.009

[8] Fornalczyk, A. and Saternus, M. (2013) Vapour Treatment Method against Other Pro- and Hydrometallurgical Processes Applied to Recover Platinum from Used Auto Catalytic Converters. Acta Metallurgica Sinica (English Letters), 26, 247-256. http://dx.doi.org/10.1007/s40195-012-0125-1

[9] Kayanuma, Y., Okabe, T. and Maeda, M. (2004) Metal Vapor Treatment for Enhancing the Dissolution of Platinum Group Metals from Automotive Catalyst Scrap. Metallurgical and Materials Transactions B, 35B, 817-824.

[10] Kim, C.H., Woo, S.I. and Jeon, S.H. (2000) Recovery of Platinum Group Metals from Recycled Automotive Catalytic Converters by Carbochlorination. Industrial \& Engineering Chemistry Research, 39, 1185-1192. http://dx.doi.org/10.1021/ie9905355

[11] Yamaguchi, K., Sekimoto, H., Kon, T., Ishizaka, A., Yoshida, T. and Honda, T. (2013) Distribution Ratios of Platinum Group Metals between the $\mathrm{Al}_{2} \mathrm{O}_{3}-\mathrm{CaO}-\mathrm{SiO}_{2}$ Slag and Molten Iron at 1873K. Proceedings of the European Metallurgical Conference EMC, Weimar, 23 -26 June 2013, Vol. 1, 267-275.

[12] Liu, G., Tokumaru, A. and Owada, S. (2013) Concentration of PGMs from Automobile Catalyst by Combining Surface Grinding and Quenching. Proceedings of the European Metallurgical Conference EMC, Weimar, 23-26 June 2013, Vol. 1, 235-253.

[13] Benson, M., Bennett, C.R., Harry, J.E., Patel, M.K. and Cross, M. (2000) The Recovery Mechanism of Platinum Group Metals from Catalytic Converters in Spent Automotive Exhaust Systems. Resources, Conservation and Recycling, 31, 1-7. http://dx.doi.org/10.1016/S0921-3449(00)00062-8

[14] Cusack, R. (2009) Rethink Your Liquid-Liquid Separations-A First Look Investigates General Principles in Designing Process Coalescers. Hydrocarbon Processing, June, 53-60. 